\title{
Effects of Rainfall Infiltration on the Stability of Soil Slopes
}

\author{
J. P. Sun ${ }^{1 *}$, Q. Q. Liu ${ }^{1}$, J. C. $\mathrm{Li}^{1}$ \\ ${ }^{1}$ Institute of Mechanics, Chinese Academy of Sciences, Beijing 100080, China \\ Email: sunjianping@imech.ac.cn
}

\begin{abstract}
Slope failure due to rainfall is a common geotechnical problem. The mechanics of rainfall induced landslides involves the interaction of a number of complex hydrologic and geotechnical factors. This study attempts to identify the influence of some of these factors on the stability of soil slope including rainfall intensity, hydraulic conductivity and the strength parameters of soil.
\end{abstract}

Key words: rainfall infiltration, slope stability, pore-water pressure, numerical modeling

\section{INTRODUCTION}

The mechanics of rainfall inducing landslides involves a number of complex hydrologic and geotechnical factors [1]. In general, hydrologic factors include rainfall intensity, duration, antecedent rainfall and total accumulation etc., and geotechnical factors include hydraulic conductivity and soil moisture with suction pressure, the saturated hydraulic conductivity and the initial water condition etc. Also, the strength parameters and physical properties of soil should be considered commonly. A numerical procedure is developed in this paper to study the effects of some of these factors on the pore pressures and slope stability.

\section{THEORETICAL BACKGROUND OF WATER FLOW AND SLOPE STABILITY}

\section{Saturated- unsaturated flow}

Same as water flow though saturated soils, water flow through unsaturated soils is governed by the Darcy's law. Combining Darcy's law and the continuity equation, transient two-dimensional saturatedunsaturated flow equation can be described by Richard's equation

$\frac{\partial}{\partial x}\left[K_{x}(h) \frac{\partial H}{\partial x}\right]+\frac{\partial}{\partial y}\left[K_{z}(h) \frac{\partial H}{\partial z}\right]=C(h) \frac{\partial H}{\partial t}$

whore: $H=h+z$ is total hydraulic head; $h$ is pressure head; $z$ is elevation head; $K_{x}$ and $K_{z}$ are the hydraulic conductivities in the $x$-direction and the $z$-direction, respectively; $C=\partial \theta / \partial h$ is the volumetric water retention capacity; and $\theta$ is the volumetric water content. The present problem is solved by a numerical finit volume approach. Further specific information on the numerical approach is reported in Fan et al[2].

\section{Slope stability analysis}

The Spencer's method[3] is used to calculate the safety factor. Figure 1 shows the details of inter-slice forces for a typical slice.

The equations of force and momentum equilibrium can be respectively written as

$$
\begin{aligned}
& P_{i}=P_{i+1}+\frac{F \Delta W \sin \alpha_{i}-c^{\prime} b \sec \alpha_{i}-\Delta W \cos \alpha_{i} \tan \varphi^{\prime}+\chi u_{i} b \sec \alpha_{i} \tan \varphi^{\prime}+\Delta Q\left(F^{\prime}-\tan \varphi^{\prime} \tan \alpha_{i}\right) \cos \alpha_{i}}{\sin \left(\beta-\alpha_{i}\right) \tan \varphi^{\prime}-F \cos \left(\beta-\alpha_{i}\right)} \\
& h_{i}=\frac{P_{i+1}}{P_{i}} h_{i+1}-\frac{P_{i+1}}{P_{i}} \frac{b}{2} \tan \alpha_{i}+\frac{b}{2} \tan \beta+\frac{P_{i+1}}{P_{i}} \frac{b}{2} \tan \beta-\frac{\Delta Q h_{a}}{P_{i} \cos \beta}-\frac{b}{2} \tan \alpha_{i}
\end{aligned}
$$

where $F$ is the safety factor; $P_{i}$ and $P_{i+1}$ are the right and the left inter-slice forces, respectively; $N_{i}$ and $u_{i}$ are the total normal force and the pore water pressure on the slice base, respectively; The 
factor $\chi$ can roughly be replaced by the relative degree of saturation for unsaturated soils and is unity for saturated soils; $\Delta W$ is the weight of slice and $\Delta Q$ is the horizontal force of slice; $\alpha_{i}$ is the angle between the slice base and the horizontal line; $\beta$ is the inclination angle of inter-slice force; $h_{i}$ and $h_{a}$ are the height of force $P_{i}$ and the center of the slice,respectively; $b$ is the width of the slice.

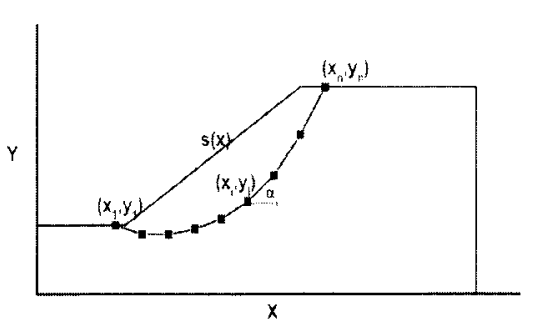

(a)

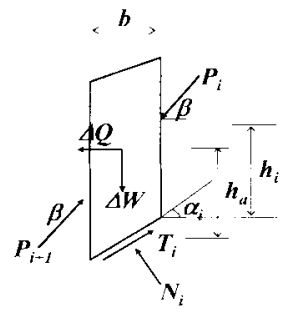

(b)

Figure 1: Schematic view of general cross section of slope (a) and forces acting on a typical slice (b)

In studying the effect of different shear strength parameters $\left(c^{\prime}\right.$ and $\left.\varphi^{\prime}\right)$ on slope stability subject to rainfall infiltration, one key problem is that different parameters give different absolute change of the safety factor. A systematic comparison would be a very formidable task. Fortunately, Janbu (1954) [4] defined a dimensionless parameter $\lambda_{\varphi \varphi}$ as

$\lambda_{c \varphi}=\gamma_{s} H \tan \varphi^{\prime} / c^{\prime}$

where $H \mathrm{i}$ s the height of slope; $\gamma_{s}$ is saturated unit weight of soils. The critical slip surface becomes more and more shallow as the value of $\lambda_{c \varphi}$ increases. When the value of $\lambda_{c \varphi}$ is equal for different shear strength parameters, the critical slip surface and the relative change of the safety of factor are the same. So the parameter $\lambda_{c \varphi}$ was used to study the effect of rainfall on slope stability in this study.

\section{RESULTS AND DISCUSSION}

A simple slope shown in Figure 2 is assumed for the simulation. The height of the slope is $10 \mathrm{~m}$. In order to simplify the problem, the slope is assumed as a homogenous and isotropic soil slope. Three different saturated hydraulic conductivities of $10^{-4}, 10^{-5}$ and $10^{-6} \mathrm{~m} / \mathrm{s}$, are assumed in order to investigate their effect on the infiltration process and the development of the pore-water pressures. Four different rainfall scenarios, $5 \times 10^{-7}, 1 \times 10^{-6}, 5 \times 10^{-6}$ and $1 \times 10^{-5} \mathrm{~m} / \mathrm{s}$ based on a distribution over the 3-day period, are devised to study the effect of rainfall intensity. Two types of soils are considered to analyze the effect of shear strength parameters. The shear strength parameters and saturated unit weights of these two soil types are as follows

Soil 1: $\gamma_{s}=19.54 \mathrm{kN} / \mathrm{m}^{3}, c^{\prime}=9.09 \mathrm{kPa}$ and $\varphi^{\prime}=25^{\circ}$, corresponding to $\lambda_{c \varphi}=10$.

Soil 2: $\gamma_{s}=19.54 \mathrm{kN} / \mathrm{m}^{3}, c^{\prime}=3.41 \mathrm{kPa}$ and $\varphi^{\prime}=35^{\circ}$, corresponding to $\lambda_{c \varphi}=40$.

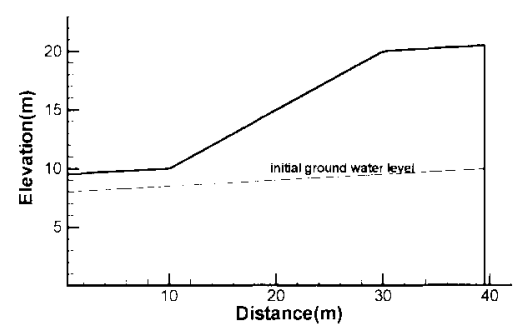

Figure 2: Geometry of the homogenous slope for the numerical analysis

Figure 3 (a)-(c) present the pore-water pressure profiles of the section located in the crest of the slope, at the end of rainfall for the saturated hydraulic conductivities of $10^{-4}, 10^{-5}$ and $10^{-6} \mathrm{~m} / \mathrm{s}$, respectively. Figure 3 (a) and (b) show that the higher the rainfall intensity is, the deeper the wetting front will be. For $K_{s}=10^{-4} \mathrm{~m} / \mathrm{s}$ (Figure 3a), when the rainfall intensity is $1 \times 10^{-5} \mathrm{~m} / \mathrm{s}$ the wetting front reache the water table and make the water table rise. For $K_{s}=10^{-5} \mathrm{~m} / \mathrm{s}$ (Figure 3b), when 
the rainfall intensity is $1 \times 10^{-5} \mathrm{~m} / \mathrm{s}$ the wetting front make the water table rise to the slope surface. For $K_{s}=10^{-6} \mathrm{~m} / \mathrm{s}$ (Figure 3c), the pressure head profiles in the end of the four different rainfall events are similar and wetting fronts are very shallow. The results indicate that the water pressure in slopes under rainfall is greatly dependent on the hydraulic conductivity. When the saturated hydraulic conductivity is low, only a very small amount of rainwater infiltrates into the ground and the most of rainwater will run off. When the saturated hydraulic conductivity is equal to or less than the rainfall intensity, the groundwater table will rise to the slope surface after the wetting front reaches the initial water table. And if the saturated hydraulic conductivity is greater than the rainfall intensity, the water table will rise but can not reach the slope surface.

The slope stability analyses for different rainfall intensities show that the greater rainfall intensity is, the lower the safety of factor of the slope will be. Figure 3d shows the simulated results of the safety factor for $K_{s}=10^{-5} \mathrm{~m} / \mathrm{s}$. When the rainfall intensity is $10^{-5} \mathrm{~m} / \mathrm{s}$, the slope has the munimum safety of factor, because the groundwater has rose to the slope surface and the slope has the highest pore-water pressure. For these two soil types, the soil 2, corresponding to $\lambda_{c \varphi}=40$, the relative change of the safety of factor is more obvious, bccause the critical slip surface is shallower and the rainfall has a great effect on the stability of slopes.

\section{CONCLUSIONS}

The water pressure in slopes under rainfall is greatly dependent on the hydraulic conductivity. When the saturated hydraulic conductivity is equal to or less than the rainfall intensity,the groundwater table will rise to the slope surface after the wetting front reaches the initial water table. The slope has munimum safety of factor in this condition. With a high dimensionless parameter $\lambda_{c \varphi}$, the slope has a shallower critical slip surface, and rainfall infiltration has a more obvious effect on the slope stability.

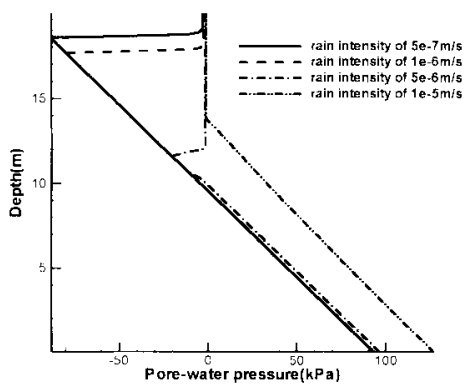

(a)

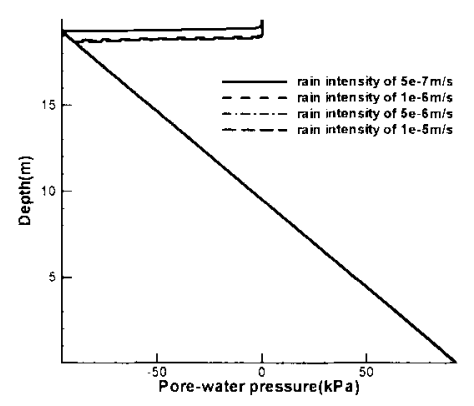

(c)

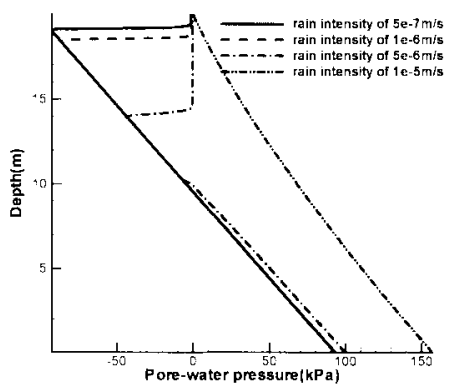

(b)

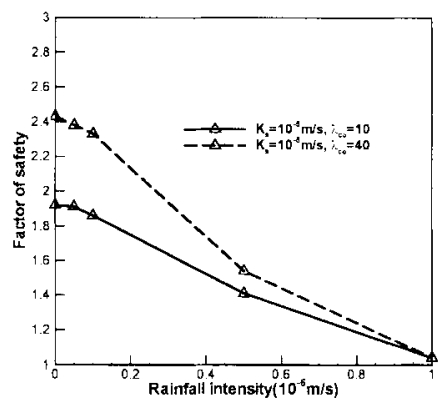

(d)

Figure 3: Pore-water pressure profiles at the crest of the slope and the safety of factor at the end of the rain (a) $K_{s}=10^{-4} \mathrm{~m} / \mathrm{s}$, (b) $K_{s}=10^{-5} \mathrm{~m} / \mathrm{s}$, (c) $K_{s}=10^{-6} \mathrm{~m} / \mathrm{s}$ (d) the safety of factor 


\section{Acknowledgements}

The support of the Knowledge Innovation Project of Chinese Academy of Sciences (No. KJCX2-SWL1-4), and the Major State Basic Research Development Program of China (No. 2002CB412703), is gratefully acknowledged.

\section{REFERENCES}

1. Ng CWW, Shi Q. A numerical investigation of the stability of unsaturated soil slopes subjected to transient seepage. Computers and Geotechnics, 1998;22(1):1-28

2. Fan P, Liu QQ, Li JC. et al. Numerical analysis of rainfall infiltration in the slope with a fracture. Science in China Ser. E, 2005;48:107-120

3. Spencer E. A method of analysis of the stability of embankments assuming parallel interslice forces. Géotechnique, 1967;17(1):11-26

4. Duncan JM, Wright SG. The accuracy of equilibrium methods of slope stability analysis. Engineering Geology, 1980;16(5):5-17 